\title{
Delayed Postanoxic Encephalopathy with Serial MRI and PET Studies
}

\author{
Hyun-Ji Cho ${ }^{a}$ Hahn Young Kim ${ }^{a, b}$ Young So ${ }^{c}$
}

${ }^{a}$ Department of Neurology, ${ }^{b}$ Center for Geriatric Neuroscience Research, Institute of Biomedical Science and Technology, and 'Department of Nuclear Medicine, Konkuk University School of Medicine, Seoul, Korea

The authors present serial MRI and PET studies in the case of a 69-year-old man with delayed postanoxic encephalopathy. Ongoing regional cytotoxic edema was observed in MRI diffusion-weighted images over a 1-year follow-up. The delayed effects of an initial hypoxic injury might be more prolonged than has been previously reported $[1,2]$.

Fig. 1. Serial MRI studies with FLAIR, diffusion-weighted imaging $\left(b=1,000 \mathrm{~s} / \mathrm{mm}^{2}\right)$ and ADC (apparent diffusion coefficients) mapping from left to right at the delayed onset of postanoxic encephalopathy (a), 6 months (b) and 13 months (c). Some lesions in both frontal white matter and the anterior corpus callosum showed persistent decreased diffusivity on diffusion-weighted imaging and ADC maps $\left(0.35 \times 10^{-3} \mathrm{~mm}^{2} / \mathrm{s}\right.$ and $0.48 \times 10^{-3}$ $\mathrm{mm}^{2} / \mathrm{s}$; mean values of regions of interest indicated by arrowheads in $\mathbf{b}$ and $\mathbf{c}$ ).

\section{KARGER}

Fax +4161306 1234 E-Mail karger@karger.ch www.karger.com
(C) 2009 S. Karger AG, Base

0014-3022/09/0615-0315\$26.00/0

Accessible online at:

www.karger.com/ene
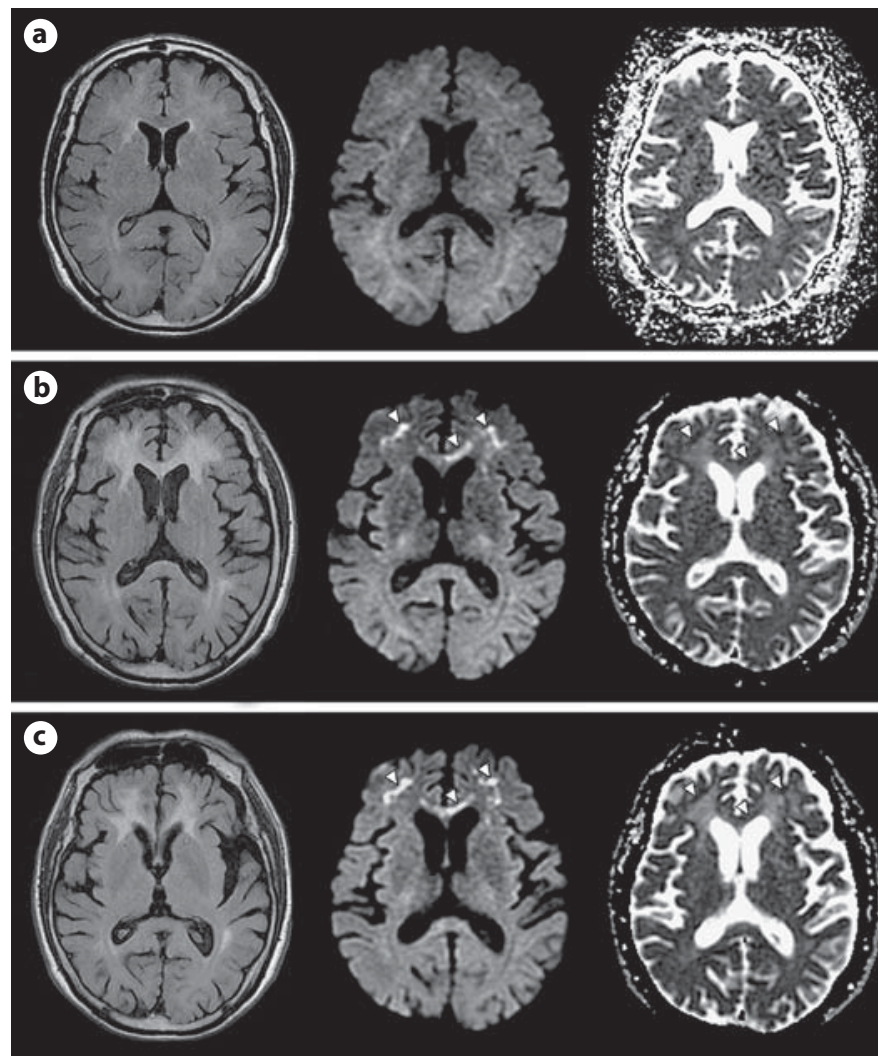

Hahn Young Kim, MD

Department of Neurology, Center for Geriatric Neuroscience Research Institute of Biomedical Science and Technology

4-12 Hwayang-dong, Gwangjin-gu, Seoul 143-729 (Korea)

Tel. +82 22030 7561, Fax +82 22030 5169, E-Mail hykimmd@gmail.com 

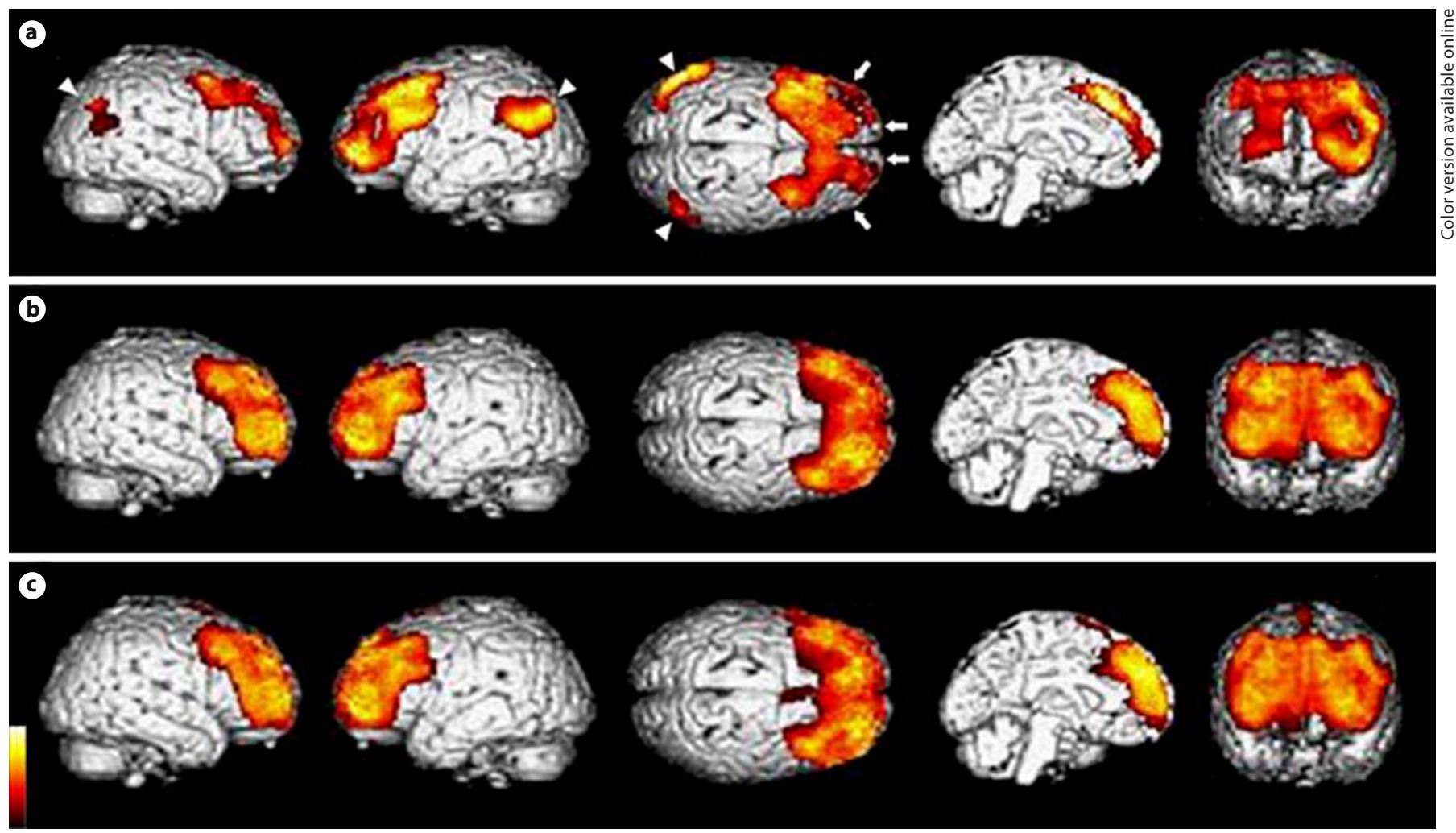

Fig. 2. Hypometabolic regions in serial PET studies at delayed onset of postanoxic encephalopathy (a), 6 months (b) and 13 months (c). Hypometabolism in both parietotemporal cortices was improved (arrowheads); however, hypometabolism in both frontal cortices was aggravated (arrows). The hypometabolic regions (yellow; color version on-line) are displayed on surface-rendered images at the threshold of $\mathrm{p}<0.001$, uncorrected $(\mathrm{t}=3.61$, $\mathrm{k}=100)$.

\section{Acknowledgment}

This work was supported by the second phase of the Brain Korea 21 project in 2008 .
References

1 Kim HY, Kim BJ, Moon SY, Kwon JC, Shon YM, Na DG, Lee KH, Na DL: Serial diffusion-weighted MR imaging in delayed postanoxic encephalopathy: a case study. J Neuroradiol 2002;29:211-215.

-2 Terajima K, Igarashi $\mathrm{H}$, Hirose M, Matsuzawa H, Nishizawa M, Nakada T: Serial assessments of delayed encephalopathy after carbon monoxide poisoning using magnetic resonance spectroscopy and diffusion tensor imaging on a 3.0T system. Eur Neurol 2008; 59:55-61. 